\title{
LEADING IN EXTREME CONTEXTS: SHARED AND VERTICAL LEADERSHIP IN THE EUROPEAN REFUGEE CRISIS
}

Katharina Kaltenbrunner, Strategic Management \& Organization, Paris Lodron University of Salzburg, Austria Ruth Simsa, Department for Socioeconomics \& Competence Center for Nonprofits and Social Entrepreneurship, Vienna University of Economics and Business, Austria

\author{
dx.doi.org/10.18374/EJM-21-1.6
}

\begin{abstract}
It increasingly solidifies in research that both vertical and shared leadership are necessary for coping with extreme contexts (Vessey \& Landon, 2017; Gibson et al., 2015; Hannah et al., 2009) but corresponding research is still in its infancy. Thus, we explore these two leadership types related to team performance in extreme contexts, illustrated by European refugee crisis in Austria. Methodologically, the paper draws on a sequential explanatory design of a mixed-method-study consisting of a mediation analysis and a qualitative study based on 57 problem centered interviews of relief teams in refugee camps all over Austria. Findings show that both leadership types are important to ensure team performance in extreme contexts. On the basis of clear condition and goals provided by vertical leadership, shared leadership in its mediating role enables the necessary common understandings, synchronized actions, flexibility, and trust to deal with the challenges.
\end{abstract}

Keywords: Shared leadership, vertical leadership, performance, extreme context, refugee crisis 